\title{
A concepção fenomenológica de verdade como elemento motivador da "virada idealista" Husserliana*
}

\author{
The phenomenological conception of truth as a \\ seminal element of the Husserlian "idealistic turn"
}

**Juliana Missaggia

\begin{abstract}
Resumo: Este artigo analisa o papel da concepção fenomenológica de verdade para a chamada "virada idealista" no pensamento husserliano. Embora normalmente não se leve em consideração a noção de verdade como elemento motivador nessa transformação da fenomenologia, pretendo demonstrar que se trata de uma das razões centrais para tal modificação. Para tanto, analiso também uma série de questões fundamentais para a compreensão do conceito de verdade na fenomenologia de Husserl, muitas vezes causadoras de interpretações equivocadas: as noções de intenção significativa, intenção intuitiva e evidência; a originalidade de tais conceitos em relação à concepção de verdade como correspondência e os diferentes tipos de verdade no pensamento husserliano, os quais mantêm uma coerência interna a despeito de suas particularidades.
\end{abstract}

Palavras-chave: Fenomenologia. Husserl. Verdade. Evidência. Idealismo.

\begin{abstract}
This paper analyzes the role played by the phenomenological conception of truth in Husserl's "idealistic turn". In the context of his transformation of phenomenology, I argue that, while usually neglected in its seminal character, Husserl's conception of truth is indeed crucial to understanding the changes underwent by his philosophy. To that end, I delve into a key set of issues - namely, the notions of meaningful intention, intuitive intention and evidence; the originality of those concepts as compared to the conception of truth as correspondence, as well as the different types of truth in Husserl's thought - all of which share a certain internal coherence, despite each one's specificities.
\end{abstract}

Keywords: Phenomenology. Husserl. Truth. Evidence. Idealism.

\footnotetext{
* Esse artigo é fruto de uma pesquisa que contou com o apoio do CNPq e da CAPES-PDSE.

** Doutora em Filosofia pela PUCRS, professora de Filosofia da Universidade Católica de Pernambuco. <jumissaggia@gmail.com>.
} 


\section{A questão sobre as razões da "virada idealista" na filosofia husserliana}

A pós a publicação de sua importante obra de 1901, Logische suposto psicologismo, Husserl passa por uma revisão de sua filosofia que resulta na chamada "virada idealista" da fenomenologia. Tal modificação de seu pensamento, surpreendente mesmo para alguns alunos próximos, é ainda hoje objeto de estudo e polêmica entre intérpretes. A opiniões se dividem tanto no que diz respeito ao que teria motivado o filósofo, como também no que concerne ao modo como devemos entender o "idealismo" por ele proposto.

Embora o debate em torno da "virada idealista" na filosofia husserliana tenha surgido a partir do primeiro volume de Ideen ${ }^{1}$ (1913), Husserl não chega a nomear sua filosofia como "idealista" nessa obra, mas desenvolve ali todas as bases daquilo que depois define como "idealismo transcendental" (transzendentaler Idealismus)2. Usualmente, considera-se que as razões principais da passagem para o idealismo seriam sobretudo a falha do projeto fenomenológico realista, tal como desenvolvido em Logische Untersuchungen, e a tentativa de estabelecer definitivamente a fundamentação última como base da filosofia.

Uma figura exemplar em torno desse debate é Roman Ingarden. O filósofo polonês desenvolveu estudos interessantes desde uma abordagem realista para a fenomenologia, tendo sido um dos alunos de Husserl que mais fortemente se opôs à "virada idealista". Ingarden criticou, desde um ponto de vista fenomenológico, diversos aspectos do projeto desenvolvido por seu professor a partir de Ideen I, questionando também quais teriam sido as razões que motivaram tal mudança. A leitura de Ingarden é fundamental, além disso, por ter sido um dos primeiros a analisar e objetar o projeto husserliano idealista influenciando amplamente interpretações "tradicionais" do idealismo transcendental, assim como diversas críticas a Husserl.

A proximidade entre os dois filósofos era grande, como atesta o amplo material disponível de correspondência entre eles, porém a divergência em relação ao tema realismo/idealismo permaneceu como um tópico de disputa jamais resolvido. Como comenta Ingarden, a respeito de um

\footnotetext{
Ideen zu einer reinen Phänomenologie und phänomenologischen Philosophie. Erstes Buch: Allgemeine Einführung in die reine Phänomenologie, doravante "Ideen I".

2 O termo é usado seguidamente principalmente a partir de 1915, e aparece em diversas obras, como Die Krisis der europäischen Wissenschaften und die transzendentale Phänomenologie: Eine Einleitung in die phänomenologische Philosophie, Cartesianische Meditationen e Formale und transzendentale Logik.
} 
encontro com Husserl em 1928: "Durante minha estadia em Freiburg jamais havíamos falado sobre isso. Mas agora Husserl me disse, ainda que brevemente: (...) "o senhor ainda verá que o idealismo transcendental é a única solução possível"3.

Ingarden entende que, no período de Logische Untersuchungen o pensamento husserliano era fundamentalmente realista, mas que uma série de fatores levaram o filósofo a assumir uma postura explicitamente idealista anos depois. O autor afirma, no entanto, que essa mudança drástica de posição filosófica não se deu da noite para o dia, mas sim foi resultado de um processo que durou mais de dez anos e que envolveu a dificuldade de lidar com algumas questões fundamentais, entre as quais a concepção de filosofia como uma ciência rigorosa e a busca por um método particular para a fundamentação última de tal ciência ${ }^{4}$.

Embora esteja de acordo que as razões normalmente apontadas como motivadoras da virada idealista sejam de fato elementos importantes, pretendo demonstrar, a partir de leituras mais recentes e à luz dos novos textos publicados, que a concepção fenomenológica de verdade é uma das razões centrais para tal transformação no pensamento husserliano. Uma boa compreensão disso, no entanto, pressupõe em primeiro lugar encontrar uma interpretação adequada para o conceito fenomenológico de verdade, assim como estabelecer em que medida tal noção se manteve ou não ao longo do desenvolvimento da filosofia de Husserl.

\section{Intenção significativa, intenção intuitiva e evidência}

O conceito de verdade da filosofia husserliana está relacionado, em primeiro lugar, com as noções de intuição (Anschauung) e evidência (Evidenz). Tais conceitos, que Husserl desenvolveu mais detidamente em Logische Untersuchungen, causam dificuldade justamente pela sua amplitude que dá margem para equivocidade. De fato, em alguns de seus escritos, Husserl usa a expressão "intuição" sem uma prévia e precisa definição, embora no interior da própria noção faça diferenciações, tais como intuição "adequada" ou "inadequada", intuição empírica (empirische Anschauung) e intuição de essência (Wesensanschauung) (Ideen I, §3). Como aponta Hintikka ${ }^{5}$, ainda que muitas vezes os intérpretes partam do princípio de que a intuição na fenomenologia seria próxima ao conceito kantiano, na verdade, em um sentido primário, intuição diria respeito a conhecimentos imediatos de qualquer tipo.

3 INGARDEN, Roman. Meine Erinnerungen an Edmund Husserl, p. 159.

4 INGARDEN, Roman. On the motives which led Husserl to transcendental idealism, p.1-2.

5 HINTIKKA, Jaakko. The notion of intuition in Husserl, p. 60. 
A noção de intuição, de fato, é por vezes conceituada de maneira bastante geral - como em Erfahrung und Urteil -, enquanto um "ver" e "experienciar" de objetos no modo como eles se mostram ${ }^{6}$. Em Logische Untersuchungen ${ }^{7}$ Husserl distingue diferentes tipos de intuição e esclarece o termo a partir do contraste entre dois modos de atos intencionais, a intenção significativa e a intenção intuitiva. Tal distinção permite evidenciar a diferença entre dois conceitos fundamentais na fenomenologia husserliana: intenção e intuição. Em poucas palavras, a intenção (Intention) é qualquer ato que envolve o dirigir-se para algo ou a apreensão de algo enquanto uma coisa que possui determinado significado, independentemente da existência ou não desse algo para além do próprio ato intencional significativo. A intuição (Anschauung), por outro lado, envolve a presença do objeto visado no ato ${ }^{8}$.

Assim, a intenção significativa (signitive Intention) diz respeito a esse ato intencional no qual o objeto visado não está presente em "carne e osso" (leibhaftig), ou seja, não há uma referência preenchida pela presença do objeto, mas apenas uma referência vazia, ainda que dotada de alguma significação particular. Não há nenhuma imagem ou percepção atual do objeto da intenção. A intenção intuitiva, por outro lado, envolve não apenas uma significação pela qual a coisa é tomada, mas também a presença direta do objeto visado, como no caso das intenções perceptivas. Desse modo, a intuição é uma intenção particular na qual o objeto se mostra à consciência "em pessoa". Como esclarece Husserl: "A intenção significativa apenas aponta para o seu objeto, enquanto que a intenção intuitiva o traz em presença".

A esses dois tipos de atos intencionais, estão conectadas diferentes noções: a intuição é uma intenção que se dá no modo da plenitude (Fülle) e do preenchimento (Erfüllung), pois trata de um objeto particular que está presente para o ato. A intenção significativa, no entanto, é uma referência vazia (Leermeinen), já que significa mas não refere a algo particular presente para o ato. Essa diferença fica clara se pensarmos nas diversas expressões de nosso discurso cotidiano que não remetem a nenhum objeto em particular mas que, ainda assim, significam algo para nós.

Husserl ressalta que a distinção entre intenções significativas e intuitivas não é algo sutil: não é o caso da defasagem entre a presença clara ou obscura de um objeto - isso, como detalharemos a seguir,

HUSSERL, Edmund. Erfahrung und Urteil, p. 421.

7 HUSSERL, Edmund. Logische Untersuchungen, VI, §21, Hua 19/1, p. 606-608.

8 Cf. DRUMMOND, John J. Historical dictionary of Husserl's philosophy, p. 110.

9 HUSSERL, Edmund. Logische Untersuchungen, VI, §21, Hua 19/1, p. 607. 
ocorre internamente ao campo da própria intuição. Trata-se, na verdade, de intenções de naturezas desiguais. Como exemplifica o filósofo, na "transição de uma intenção significativa para a intuição correspondente experienciamos não apenas um mero aumento, como na mudança de uma imagem desbotada ou um mero esboço para uma pintura plenamente vivaz" ${ }^{10}$, o que ocorre é antes uma mudança essencial na intenção como no caso da mera referência de uma pintura nunca antes vista a qual a pessoa só conhece pelo nome, para o posterior preenchimento da intenção pela presença da própria pintura, quando a pessoa tem acesso à obra.

A importância dessa diferença e sua relação com o conhecimento fica manifesta diante da necessidade de encontrar um critério para definir o que é verdadeiro e falso. Husserl encontra tal critério a partir da noção de evidência (Evidenz), que diz respeito justamente à possibilidade de preenchimento adequado do ato intencional, à intuição preenchida. Um ato intencional envolve evidência quando aquilo que é intencionado no ato significativo está em total correspondência com o que é dado; quando, portanto, o preenchimento é apropriado:

[Na evidência] o objeto não é apenas significado, mas em sentido estrito ele é dado, e dado tal como é significado (...). A própria evidência é um ato do tipo mais perfeito de correspondência. Como toda identificação, ela é um ato objetificante, sendo o seu correlato objetivo ser no sentido da verdade, ou simplesmente verdade $(\ldots)^{11}$.

Assim, há uma relação direta entre evidência e verdade, pois sendo evidente um ato onde há perfeita correspondência entre aquilo que é apreendido significativamente e aquilo que é dado "em pessoa", será esse o critério para determinar o que é verdadeiro e, portanto, o que pode propriamente ser tomado como conhecimento. Além disso, Husserl se refere, na passagem citada, à evidência como um ato objetivante (objektivierender Akt). Esses dizem respeito a todo ato que faz referência a um objeto, que presenta algo enquanto algo objetivo, de modo que inclui tanto atos predicativos, como pré-predicativos, seja um ato nominal (que dá nome a um objeto), seja um julgamento ou uma percepção. Não objetivante são todos os atos nos quais não há referência direta ao objeto, mas antes tratam da maneira pela qual o objeto é dado, como desejos e sentimento ${ }^{12}$.

10 Ibidem.

11 HUSSERL, Edmund. Logische Untersuchungen, VI, §38, Hua 19/1, p. 651. Ver também HUSSERL, Edmund. Cartesianische Meditationen, §26, Hua 1, p. 95.

12 HUSSERL, Edmund. Logische Untersuchungen, V, §37, Hua 19/1, p. 496-499. 
Reformulando algumas análises de Brentano, Husserl sustenta que todo ato ou é objetivante ou baseia-se em um tal tipo de ato ${ }^{13}$. Além disso, os atos objetivantes podem tanto ser posicionais (setzender Akt) ou não posicionais, no caso dos primeiros o objeto é visado como algo que existe (como nas percepções e memórias), no caso dos segundos, não há referência à sua existência (como nas fantasias), e o objeto pode ser tomado como uma mera presença. A evidência, portanto, é um ato no qual necessariamente há a presença de algo enquanto algo objetivo, entendendo por "objetivo" não apenas um objeto individual, mas também um estado de coisas (Sachverhalt), isto é, o correlato ou o objeto intencional de determinado ato de intencionalidade.

\section{A originalidade dos conceitos de evidência e verdade}

É importante observar que essas análises sobre os critérios para o conhecimento verdadeiro, embora desenvolvidas mais amplamente no período de Logische Untersuchungen, são mantidas e aperfeiçoadas na chamada fase da virada "idealista" de Husserl, quando o filósofo reitera a necessidade de encontrar na evidência o "princípio de todos os princípios" que serve de fundamento para o conhecimento seguro, agora reforçada pela noção de intuição pura, coerente com o ponto de partida da redução fenomenológica: "é preciso manter-se fiel ao "princípio de todos os princípios', segundo o qual a clareza perfeita é medida da verdade"14. De fato, não haveria qualquer outro critério possível para distinguir o verdadeiro do falso senão a própria noção de evidência e é a partir dessa base que o conhecimento fenomenológico deve ser desenvolvido:

13 “(...) Husserl afirma que a tese de Franz Brentano de que todo ato é ou uma presentação ou fundado em uma presentação é reinterpretada com a afirmação de que toda experiência intencional é ou um ato objetificante ou fundado em um ato objetificante" (DRUMMOND, John J. Historical dictionary of Husserl's philosophy, p. 149). Ver BRENTANO, Franz. Psychologie vom empirischen Standpunkte, p. 104-115.

14 HUSSERL, Edmund. Ideen I, \$78, p. 151 e 174. Nas Meditações Cartesianas, Husserl define evidência do seguinte modo: "evidência (...) designa o modo de consciência bem preeminente da autoaparição, do apresentar-se a si próprio, do dar-se a si próprio de uma coisa, de um estado de coisas, de uma generalidade, de um valor, etc., no modo final do ele próprio aí, imediata, intuitiva e originalmente dado" (HUSSERL, Edmund. Cartesianische Meditationen, §24, p. 92-94). Observação sobre traduções: para a citação das obras de Husserl utilizamos, geralmente, o nome reduzido do livro ("Krisis", por exemplo), seguido da paginação no original e, quando disponível, da página correspondente na tradução em língua portuguesa, a qual citamos. Eventualmente alteramos a tradução, casos nos quais acrescentamos "t.a.", "tradução alterada". Nas obras utilizadas para as quais não há tradução em nosso idioma, a tradução citada é de nossa responsabilidade. 
É preciso frisar que nosso reiterado recurso à clareza intuitiva (evidência, isto é, intuição), nãoé, aquicomoem partealguma, uma mera frase, masexprime (...) o recuo àquilo que há de último em todo conhecimento, exatamente como se fala de evidência nos axiomas lógicos e aritméticos mais primitivos ${ }^{15}$.

Algo a ser destacado, porém, é que evidência nada tem a ver com qualquer espécie de "sentimento" de que algo é verdadeiro. Husserl é bastante claro em afastar da noção de evidência qualquer traço de psicologismo, de modo que não podemos conectar à noção de evidência o mero sentimento subjetivo. De fato, se dependermos de estados psicológicos subjetivos como critério para determinar o verdadeiro do falso, necessariamente cairemos em contradições, pois um mesmo ato intencional pode nos despertar sentimentos de dúvida ou certeza dependendo de fatores exclusivamente subjetivos e cambiantes, como nosso estado emocional. Husserl descreve as obscuridades metodológicas a serem evitadas:

Fala-se, é verdade, em evidência, mas em vez de colocá-la, como evidência, em relações de essência com o ver habitual, recorre-se a um 'sentimento de evidência', que, como um index veri místico, empresta ao juízo uma coloração emotiva. Tais apreensões são possíveis somente enquanto ainda não se aprendeu a analisar os tipos de consciência em visão pura e na forma de essências, em vez de fazer, de cima para baixo, teorias a respeito deles. Esses supostos sentimentos de evidência, de necessidade do pensar e como quer que ainda possam ser chamados, não passam de sentimentos inventados teoricamente ${ }^{16}$.

Será também com base na noção de evidência que Husserl irá criticar a posição cética, uma vez que essa necessariamente cai em contradição ao tentar refutar a possibilidade de conhecimento apelando justamente para argumentos baseados no próprio critério de evidência, enquanto único meio possível para determinar o verdadeiro e distingui-lo do falso. No debate com o cético, não é o caso de discutir e contrastar duas concepções distintas de verdade, mas sim a impossibilidade mesma do debate, uma vez que o interlocutor ao mesmo tempo utiliza e nega a capacidade fundamental que se encontra na base de qualquer noção de verdade: a possibilidade de distinguir algo como claro e evidente.

Isso não significa, porém, que a concepção de conhecimento na fenomenologia apele para um rigor tal que apenas axiomas lógicos sejam tomados como verdadeiros. De fato, há graus de evidência mais

15 HUSSERL, Edmund. Ideen I, §79, p. 157, p. 180.

16 Ibidem, §21, p. 39, p. 65. O filósofo reitera o mesmo em outras obras, como Einleitung in die Logik und Erkenntnistheorie (Hua 24, p. 156) e Die Idee der Phänomenologie (Hua 2, p. 59). 
e menos "seguros", e faz parte do modo mesmo como conhecemos que determinados objetos sejam conhecidos mais facilmente do que outros: de modo geral, temos mais segurança na correção de um cálculo matemático do que em uma experiência perceptual. É reconhecendo essas diferenças que Husserl distingue diversos modos de evidência, que estão sempre relacionadas com o modo como o objeto apresenta-se e ao tipo de preenchimento intuitivo: temos, assim, evidências apodíticas (indubitáveis de essências), evidências assertóricas (apercepção de algo individual), evidências inadequadas (passíveis de aumento ou diminuição a partir de novas evidências) e adequadas (exaustiva, sem aumento de

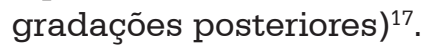

Da mesma maneira, é natural que em diversos modos de atos intencionais devamos estar sempre cientes da possibilidade de revisão da intuição. É o caso, por exemplo, de um determinado ato perceptivo enganoso que, através de outro ato, é corrigido. O ponto central, porém, é que não há outro meio para a revisão e correção que não a própria evidência. Portanto, não é o caso que uma evidência jamais possa mostrar-se falha, mas sim que esse é o único critério de que dispomos para alcançar algo que possamos chamar de conhecimento (Ideen I, $\S 122-5)^{18}$.

A possibilidade ou necessidade de correção e revisão, portanto, não é uma demonstração de algum tipo de "imperfeição", pois o fato de que nossa capacidade de conhecer se dê desse modo é uma condição que deve ser constatada na elaboração de qualquer teoria do conhecimento. O equívoco residiria justamente no contrário: tomar as condições particulares de determinadas formas de saber (como a percepção de qualquer objeto ser sempre parcial) como uma imperfeição, partindo de um pressuposto de exigência alheio ao modo de se mostrar do objeto, é um engano a ser evitado. A consequência de não tomar tal cuidado é evidente: não poderíamos considerar como um saber efetivo nada além dos axiomas lógicos e matemáticos mais elementares.

O erro por trás desse tipo de procedimento na elaboração de teorias do conhecimento - tal como exigir evidência adequada ou apoditicidade para a percepção de objetos transcendentes - situa-se em uma concepção prévia e equivocada sobre o que podemos ou não tomar como saber seguro. O que falta, segundo Husserl, é ser fiel ao princípio, conhecido

17 HUSSERL, Edmund. Ideen I, §137, §138, p. 317-320. Não cabe aqui uma análise exaustiva dos tipos de evidência. Para um aprofundamento do tema, ver STRÖKER, Elisabeth. Husserls Evidenzprinzip. Sinn und Grenzen einer methodischen Norm der Phänomenologie als Wissenschaft, VÁSOUEZ, Guillermo Hoyos. Von der Adäquaten zur Apodiktischen Evidenz e MCGILL, V. J. Evidence in Husserl's Phenomenology.

18 Ver também HUSSERL, Edmund. Formale und transzendentale Logik (Hua 17, p. 130, ss). 
desde Aristóteles ${ }^{19}$, segundo o qual de cada coisa devemos esperar o grau e tipo de evidência que lhe é própria e possível, de acordo com o modo de ser da coisa (Ideen I, §52). Nesse sentido, também, podemos questionar em que medida a filosofia husserliana é intelectualista em relação à teoria do conhecimento.

Esse ponto, ao qual voltaremos adiante, é fundamental para entender no que consiste o projeto fenomenológico e a sua originalidade em relação a outras filosofias, pois ainda que a crítica husserliana ao ceticismo seja bastante tradicional e sua concepção de verdade pareça se inserir no grupo das doutrinas clássicas da consciência, a maneira como o filósofo irá conduzir a justificativa para o conhecimento verdadeiro, à luz da concepção de redução fenomenológica, está entre os fundamentos que motivaram a novidade trazida pelo idealismo transcendental.

Um primeiro indício desse aspecto, que já pode ser destacado, é a diferença entre a concepção de verdade apresentada por Husserl e a tradicional concepção de verdade como correspondência. De fato, à primeira vista, os conceitos de verdade e conhecimento na fenomenologia podem parecer bastante tradicionais: verdade é definida como a total concordância entre aquilo que é intencionado e aquilo que é dado enquanto $\mathrm{tal}^{20}$ e conhecimento como a identificação entre aquilo que é intencionado e aquilo que é dado, em plena conexão com a noção de evidência ${ }^{21}$.

No entanto, não devemos entender esse "dado" como um estado de coisas independente da consciência. Embora essas análises partam do contexto de Logische Untersuchungen, elas se mantêm, ainda que com alguns desenvolvimentos, a partir da "virada idealista" de Husserl. É o caso, por exemplo, do conceito de verdade apresentado nas Meditações Cartesianas, quando o filósofo define: "Na fundamentação autêntica [do conhecimento], os juízos mostram-se como corretos, como concordantes, ou seja, a fundamentação é a concordância do juízo com a própria situação julgada (com a coisa ou o estado de coisas)"22.

Nesse sentido, também aqui não se deve perder de vista a redução fenomenológica, que impede análises sobre objetos puro e simples, tal como concebidos na atitude natural. Desse modo, a clássica teoria da verdade como correspondência, de um lado, diz respeito à relação entre a consciência e o objeto puro e simples (dois domínios, portanto, ontologicamente distintos), de modo que a verdade ocorre quando há

\footnotetext{
19 Aristóteles, Ética a Nicômaco, 1094 b 24-7. Ver RUSSELL, Matheson. Husserl: A Guide for the Perplexed, p. 103.

20 HUSSERL, Edmund. Logische Untersuchungen, VI, §39, Hua 19, p. 651-652.

21 Ibidem, VI, Hua 19, p. 539.

22 HUSSERL, Edmund. Cartesianische Meditationen, §4, Hua 1, p. 48 e 51.
} 
adequação entre a coisa intencionada, pensada ou julgada e a "realidade" enquanto estado de coisas independente da consciência.

A concepção de verdade fenomenológica, por outro lado, entende a correspondência como a coincidência entre duas intenções, uma meramente significativa e outra intuitiva. Ou seja, não se trata de campos ontológicos diversos, mas de uma adequação entre dois atos pertencentes ao mesmo campo da consciência transcendental e, portanto, ao mesmo domínio ontológico ${ }^{23}$. O ponto chave é entender o papel do preenchimento da intenção, que garante a apreensão de uma evidência e não de uma mera intenção significativa porém vazia de preenchimento ${ }^{24}$.

É importante ressaltar, ainda, que embora Husserl parta de uma teoria da evidência semelhante a de Descartes, ele precisa justificar sua concepção de evidência a partir de outras bases: ao contrário do projeto cartesiano, ainda imbuído, segundo o filósofo alemão, de uma "escolástica escondida, como um preconceito não esclarecido" 25 , a fenomenologia não pode se valer da ideia de um Deus veraz e bondoso como garantia da veracidade do que nos é dado como evidente ou, nos termos cartesianos, como claro e distinto. Se isso já se mostrou um problema difícil para Descartes - acusado, já por seus contemporâneos, de ter formulado um argumento circular $^{26}$-, para Husserl, conforme veremos adiante, a dificuldade parece ainda maior.

${ }^{23}$ Descrever, porém, a maneira como Husserl irá justificar essa coincidência ontológica e sua concepção de conhecimento de modo geral certamente não é tarefa fácil, nem pode ser resumida em poucas linhas, transcendendo os limites desse estudo. Ainda assim, adianto, a seguir, alguns pontos centrais em torno desse debate.

24 Cf. RUSSELL, Matheson. Husserl: A Guide for the Perplexed, p. 104-5 e ZAHAVI, Dan. Husserl's Phenomenology, p. 31-32.

25 HUSSERL, Edmund. Cartesianische Meditationen, §10, Hua 1, p. 61-62.

26 A regra da clareza e da distinção, nas Meditações Metafísicas, serve como uma "regra da verdade", pois é a partir dela que se tem a garantia de que as ideias são verdadeiras: se algo é concebido clara e distintamente, é verdadeiro. Embora essa regra seja "validada" apenas na quarta meditação, ela já aparece, explicitamente, na terceira meditação. Esse problema em torno do aparecimento da regra da verdade é uma das formulações do chamado "círculo cartesiano". A dificuldade se dá pelo fato de que a regra da clareza e da distinção surge, na terceira meditação, antes da certeza da existência de Deus; mas é somente na quarta meditação, através da ideia de um Deus veraz e bom, que tal regra obtém a "prova" de sua validade. Em poucas palavras: Deus é sumamente perfeito e, por isso, não iria jamais nos enganar; há, também, uma propensão natural nos seres humanos para consentir com aquilo que é percebido clara e distintamente (e não lhes foi dada nenhuma faculdade que corrija tal inclinação), do que se segue que o que é percebido clara e distintamente deverá ser verdadeiro, caso contrário, Deus seria enganador. A dificuldade, portanto, é que Descartes recorre à "clareza e distinção" em diversos pontos da terceira meditação - como por ocasião de uma reflexão sobre a certeza da existência de si como "coisa pensante", único conhecimento seguro até o momento -, assim como para a própria prova da existência de Deus. Cf. DESCARTES, René. Méditations métaphysiques e GUEROULT Martial, Descartes selon l'ordre des raisons. 


\section{As diferentes definições de verdade e sua coerência}

Analisando escritos posteriores de Husserl, vemos ainda que o filósofo distingue - como na obra de 1929, Formale und Transzendentale Logik - dois conceitos de verdade aos quais se conectam dois conceitos de evidência: no primeiro sentido, verdade diz respeito à adequação de um juízo a determinado estado de $\operatorname{coisas}^{27}$ ("efetividade") dados claramente ("por si mesmo") à consciência. No segundo sentido, que está na base do primeiro, verdade é aquilo que se mostra como efetivo e realmente existente, de modo que não duvidamos de sua presença e veracidade. Os conceitos correspondentes de evidência são o que permite os dois sentidos de verdade: no segundo sentido, a própria presença clara do estado de coisas "efetivo"; no primeiro sentido, aquilo que serve de critério e acompanha o juízo verdadeiro: esse só pode ser assim considerado quando está de acordo com uma evidência dada. Nas palavras de Husserl:

Além do conceito crítico de verdade, o conceito da correção de um juízo através da sua correção presente ou passada à efetividade [Wirklichkeit] por si mesma dada, temos também o conceito de efetividade como um segundo conceito de verdade. A verdade é agora o efetivamente ou realmente existente, enquanto o correlato da evidência [Evidenz] que dá a si mesma. Naturalmente, o efetivo [das Wirkliche] no sentido do real [des Realen] é apenas um caso particular desse conceito alargado e analítico-formal de efetividade. A palavra evidência também é tomada, em conexão com esses dois conceitos de verdade, em dois sentidos: além de significar o ter original próprio de um ser efetivo ou verdadeiro, evidência também significa a propriedade pertencente ao julgamento (...) quando ele está de acordo, na atualidade [Aktualität] original, com uma efetividade correspondente ${ }^{28}$.

A esses dois conceitos, Sokolowski denomina verdade como correção (correctness) e verdade como manifestação (disclosure) ${ }^{29}$. Segundo o intérprete, a diferença fica clara se levarmos em conta que a

27 Também aqui vale a ressalva feita anteriormente: Husserl parte sempre da redução fenomenológica, portanto não devemos entender "estado de coisas" e "efetividade" nesse contexto como tratando da realidade pura e simples tal como concebida na atitude natural.

28 HUSSERL, Edmund. Formale und transzendentale Logik. Hua 17, p. 133. Opto por traduzir Wirklichkeit sempre como "efetividade", mesmo nos casos em que o termo é usado em um sentido mais amplo, como nessa passagem (sentido pelo qual o próprio Husserl chama a atenção na passagem citada). O significado do conceito nesse contexto - enquanto um estado de coisas dado de maneira evidente à consciência - não deve ser confundido, portanto, com seu uso mais restrito, enquanto realidade "pura e simples", tal como dada na atitude natural. Embora muitos prefiram traduzir o termo como "atualidade" isso gera problemas no momento de diferenciar Wirklichkeit de Aktualität, como também seria o caso aqui.

29 SOKOLOWSKI, Robert, Introduction to Phenomenology, p.158-159. 
primeira sempre diz respeito a um juízo ou sentença que necessita de confirmação através de uma evidência. O segundo conceito, por outro lado, seria verdade em um sentido mais elementar, e que não necessita de confirmação; ao contrário, pode ser justamente o que permite a confirmação da verdade enquanto correção: trata-se da presença de um estado de coisas inteligível, qualquer objeto que se apresente como algo real e atual para a consciência. Nesse caso, portanto, não há um juízo prévio a ser confirmado ou não, mas a manifestação mesma de algo como um dado cuja presença ou modo de ser não desperta dúvidas ${ }^{30}$.

No que diz respeito à evidência, Sokolowski reconhece os dois sentidos como correspondentes aos dois conceitos de verdade apresentados: quanto à verdade como correção, a evidência serve como o critério de avaliação da veracidade ou não da sentença ou juízo, ela é o que permite a verificação; no caso da verdade como manifestação, a evidência é justamente o que acompanha a presença do objeto ou estado de coisas: a coisa mesma apresenta-se no modo de uma evidência, isto é, como algo claro e distinto para a consciência ${ }^{31}$.

Esse sentido duplo de verdade parece ser, em última instância, um resumo ou compilação daquilo que o filósofo havia desenvolvido anteriormente. De fato, encontramos uma distinção ainda mais detalhada da amplitude que o conceito de Wahrheit pode abranger na fenomenologia, a qual determina quatro tipos ou significados de verdade ${ }^{32}: 1$ ) em primeiro lugar, verdade diz respeito à experiência atual da correspondência adequada entre o objeto tal como concebido na intenção significativa e na intuição preenchida, quando da sua presença clara para a consciência (uma experiência específica da verdade como "correção", nos termos de Sokolowski); 2) verdade é também a ideia mesma de relação adequada presente em qualquer ato de correspondência, enquanto uma ideia essencial necessária para a consciência ao conceber algo como correto; ou seja, verdade aqui diz respeito não a uma experiência presente de correspondência em particular, como no primeiro sentido, mas à "ideia de uma adequação absoluta enquanto tal", que garante a possibilidade de constatar sua aplicação em um ato atual ${ }^{33}$; 3) verdade enquanto o

30 Sobre a objeção de que há ambiguidade no conceito de verdade em Husserl, Dupre (DUPRE, Louis. The Concept of Truth in Husserl, p. 353) responde adequadamente: "A resposta para essa objeção é que o conceito de verdade ele mesmo possibilita a distinção, e que tal distinção de modo algum implica em inconsistência. Os dois tipos de verdade são intimamente relacionados. Haveria inconsistência se um excluísse o outro, como no caso de uma verdade lógica imanente de um lado, e uma verdade intuitiva transcendente de outro. É óbvio que se a verdade consiste na intuição mental de uma realidade exterior, ela não poderia dizer respeito à uma estrutura lógica pura. Mas Husserl deixa claro que as coisas que são dadas no julgamento verdadeiro não são de modo algum realidades exteriores".

31 SOKOLOWSKI, Robert, Introduction to Phenomenology, p. 162.

32 HUSSERL, Edmund. Logische Untersuchungen, Hua 19/1, VI, §39, p. 651-653.

33 Ibidem, Hua 19/1, VI, §39, p. 652. 
"verdadeiro": a própria coisa enquanto critério de correção que serve de base para o julgamento sobre a veracidade. Nesse caso, seria a coisa intuída em contraste com a coisa meramente intencionada como significativa (antes de seu preenchimento intuitivo). Trata-se de um sentido semelhante à verdade como "manifestação", mas aqui em comparação com a mera intenção significativa do objeto. 4) Por fim, temos o conceito de verdade como a correção de um juízo: um julgamento mostra-se verdadeiro quando corresponde adequadamente a um estado de coisas, tal como dados na evidência ${ }^{34}$.

É interessante ressaltar que os conceitos de verdade desenvolvidos por Hussserl - seja no período de Logische Untersuchungen, seja em períodos posteriores, como em Formale und Transzendentale Logik - não limitam-se à noção de verdade como correspondência entre dois objetos de esferas ontológicas distintas (o "juízo" ou "ideia" em adequação com a "realidade" ou um "estado de coisas" independente), nem tampouco estão restritos à análise lógica de juízos e proposições, ainda que também digam respeito a essa esfera. A fenomenologia, de fato, trata do conceito de verdade como uma experiência muito mais basilar, na qual está assentada a possibilidade do juízo verdadeiro ${ }^{35}$. O problema, no entanto, é como determinar e justificar a relação de correspondência, principalmente no contexto "realista" na primeira fase de Husserl, o que cabe, portanto, analisar brevemente.

\section{A noção de verdade como elemento motivador da "virada idealista"}

Ainda que tanto no período de Logische Untersuchungen quando em obras posteriores Husserl estabeleça uma relação de identidade entre evidência e verdade, e que as análises da obra de obra de 1901 se mantenham, ao menos a esse respeito e a grosso modo, nos escritos posteriores, há controvérsias sobre em que medida e com quais limites a teoria da verdade se modificou a partir da chamada "virada idealista"

34 Como analisa Russell (RUSSELL, Matheson. Husserl: A Guide for the Perplexed, p.106), esse conceito de verdade é paralelo ao aristotélico, segundo o qual uma sentença é verdadeira se diz o que é o caso (Aristóteles, Metafísica, 1011 b 25-30). Nas análises de Husserl se trata, portanto, de um conceito de verdade que pressupõe os anteriores.

35 É também digno de nota a grande influência de Husserl nas concepções de verdade pregadas por outros fenomenólogos, como Heidegger e Merleau-Ponty, o que por vezes passa despercebido aos estudiosos. Quando Heidegger se refere, por exemplo, à verdade "antepredicativa" e ao "desvelamento" e afirma ser o conceito tradicional de verdade como correspondência algo fundado em um conceito anterior e mais fundamental, o filósofo não está tão distante de seu professor. Ver HEIDEGGER, Martin. Sein und Zeit, p. 213-219, Heidegger, Martin. Vom Wesen des Grundes, p. 11-17. Para um estudo sobre as diferenças entre as concepções de verdade de Husserl e Heidegger, ver TUGENDHAT, Ernst. Heideggers Idee von Wahrheit, assim como o importante trabalho de Tugendhat: Der wahrheitsbegriff bei Husserl und Heidegger, esclarecedor também no que diz respeito especificamente ao conceito de verdade em Husserl. 
da fenomenologia. Ingarden comenta, a partir de suas considerações sobre a concepção de verdade das Investigações Lógicas, que Husserl teria rejeitado muito do que havia desenvolvido nesse período ${ }^{36}$.

Segundo Günther Patzig não podemos compreender os desenvolvimentos posteriores como apenas um complemento em relação ao que foi estabelecido nas primeiras obras de Husserl, pois por trás da identificação entre evidência e verdade, podemos encontrar duas concepções com resultados bastante distintos: uma coisa é entender a verdade como fundada na evidência, de modo a alegar que só podemos tratar da verdade como algo com sentido quando há evidência, e outra coisa é reduzir verdade à evidência, como sendo uma e a mesma coisa. Segundo o intérprete, essa é uma diferença fundamental entre os escritos da chamada fase "realista", que adota a segunda opção, e aqueles da fase "idealista", que adota a primeira ${ }^{37}$.

Em Logische Untersuchungen Husserl entenderia o julgamento evidente como algo que é, ao mesmo tempo, um caso particular e uma experiência da ideia de verdade, e desenvolveria uma teoria de identidade tal que não poderia haver graus de evidência, pois, dada a identificação com verdade, isso abriria margem para dizer que algo é "mais ou menos" verdadeiro, ou um pouco verdadeiro e um pouco falso, contrariando axiomas lógicos fundamentais ${ }^{38}$. Um julgamento evidente seria composto por três momentos: o ato de julgar, a percepção de um estado de coisas (seja ideal ou real) e o insight de que aquilo que é expresso no juízo corresponde de fato ao estado de coisas percebido ${ }^{39}$. Haveria, portanto, a necessidade de estabelecer uma ponte que garantisse o sucesso do insight, uma justificativa adequada para a ponte entre o juízo e o estado de coisas percebido que garantisse sua objetividade ${ }^{40}$.

Segundo a leitura de Patzig, foi justamente a falha em encontrar uma justificativa adequada para a noção de evidência, assim como a sua relação com a verdade nesses termos, que conduziu Husserl ao idealismo.

36 "A evidência 'oral' de que Husserl considerou sua posição (...) como falsa foram suas palavras em uma conversa comigo no outono de 1927. Quando ele perguntou qual foi o assunto das minhas aulas na Universidade de Lwów, eu disse que em uma delas eu li, entre outras coisas, o primeiro volume das Investigações Lógicas, especialmente o último capítulo. Husserl respondeu: 'Ach, warum haben Sie dies gelesen, da habe ich mich so verrannt' [Ah, por que o senhor leu isso, eu me equivoquei muito ali]" INGARDEN, Roman. On the motives which led Husserl to transcendental idealism, p. 8. Vale ressaltar, também, que essa é uma das razões pelas quais optamos por analisar a concepção das Investigações Lógicas, no que diz respeito à concepção de verdade, a partir do segundo volume.

37 PATZIG, Günther. Husserl on Truth and Evidence, p. 179. Ver também ver PATZIG, Günther. Kritische Bemerkungen zu Husserls Thesen über das Verhältnis von Wahrheit und Evidenz.

38 PATZIG, Günther. Husserl on Truth and Evidence, p. 187-188.

39 Ibidem, p. 191-192.

40 Ibidem, p. 194. 
A dificuldade por trás do desenvolvimento da noção residia em parte na concepção de lógica pregada pelo filósofo nesse período, que procurava justificá-la como uma ciência que investiga fatos objetivos (relações de objetos ideais, unidades ideais de significado, etc.), os quais seriam apreendidos a partir de um insight intuitivo ${ }^{41}$. Husserl acabaria, ao fim, por estabelecer um argumento circular para fundamentar sua concepção de lógica: ele refere-se à noção de evidência para justificar a existência de objetos ideais, mas na própria noção de evidência (identificada de antemão com verdade) ele pressupõe que é evidente o acesso a tais objetos como existentes e, portanto, que é verdadeira sua existência objetiva $^{42}$.

A enigmática virada idealista de Husserl (...) pode ser em parte compreendida se considerarmos que ele foi levado à virada pela tensão das mesmas dificuldades que se apresentaram contra sua teoria da evidência. No lugar do problema de como verificar uma realidade objetiva, surge o problema da constituição de um mundo unificado de objetos intencionais da consciência pura. Se a evidência para o primeiro Husserl era a ponte entre ato e objeto, garantindo sua verdade, agora não é nem necessário nem adequado construir tal ponte, uma vez que a fundamentação cartesiana foi adotada em uma formulação husserliana. A separação entre ato e objeto que inicialmente precisava de uma ponte, agora desaparece: temos o mundo de antemão em nossas cogitationes, e fenomenologia pode agora ser entendida como a descrição e análise da constituição do mundo em nossos atos de consciência. (...) É somente no contexto de uma posição estritamente idealista que é possível manter, sem contradição, uma identidade entre evidência e verdade. É surpreendente o preço que Husserl paga para salvar sua teoria da evidência. Um preço que parece excessivamente alto, de modo que preferiríamos rejeitar essa tese atrativa $(. .)^{43}$.

Assim, Patzig entende que a necessidade de justificar a objetividade foi responsável pela teoria da identificação entre evidência e verdade, mas que as falhas na sua argumentação, reconhecidas posteriormente por Husserl, o conduziram para o idealismo, no qual poderia manter sua teoria - embora também a tenha reformulado, a partir da abertura dada pelo novo contexto. O idealismo seria uma solução atraente na medida em que previne contra a necessidade de buscar uma ponte entre ato e objeto, já que os próprios atos constituem os objetos. Segundo o intérprete, portanto, Husserl prefere ser levado ao idealismo do que abrir mão de sua teoria da verdade, o que constitui uma falha grave no seu pensamento.

41 Ibidem, p. 195.

42 Ibidem, p. 192.

43 Ibidem, p. 192. 
Levinas desenvolve uma análise que vai, em parte, na mesma direção. Ele mostra que Maurice Pradines, em um dos primeiros trabalhos publicados na França acerca da filosofia husserliana ${ }^{44}$, criticava justamente esse aspecto que Patzig aponta como sendo o problema que Husserl evitou ao converter sua filosofia em um idealismo: para manter a concepção de verdade em sua conexão com a intuição preenchida (a evidência), seria necessário explicar a relação entre a intuição e a coisa a qual ela se dirige. Em outras palavras, partindo de um ponto de vista realista, é necessário explicar como se tem garantias de que a intuição foi realmente preenchida de maneira correta e que a suposta evidência de fato corresponde com o estado de coisas ao qual a consciência teria acesso.

A dificuldade que Pradines percebe na intuição, que é incapaz de explicar 'o enigma' de sua própria transcendência, não abrange o caráter intencional da consciência. (...) Como podemos confiar em uma intuição que pretende apreender o ser, um ser que na hipótese realista existe por si mesmo? Como, quando descrevemos os dados intuitivos, podemos ultrapassar a esfera da 'descrição psicológica' e obter asserções ontológicas? (...) Para responder a tais objeções, nós precisamos voltar à noção husserliana de ser, (...) o realismo de Logische Untersuchungen foi apenas um estágio na elaboração da fenomenologia, e o que agora é chamado de idealismo de Ideen deve aparecer para fornecer um valor ontológico para os dados da intuição. O idealismo de Ideen é um idealismo intencional e consequentemente concebe de uma nova maneira o modo de existir e a estrutura da consciência, assim como a existência 'fenomênica' das coisas. O idealismo parece resolver o 'enigma da intuição'45.

Levinas entende, portanto, que essa dificuldade só se configura no contexto do realismo de Logische Untersuchungen, mas não no idealismo de Ideen. Segundo sua leitura, o idealismo transcendental, ao contrário de evitar fazer asserções ontológicas - ou nem mesmo dever fazê-las -, como sustentam alguns intérpretes ${ }^{46}$, permite justamente uma investigação ontológica das coisas elas mesmas. Isso se torna possível, tal como apontou Patzig, por toda a "realidade" ser constituída na própria consciência, de modo que não é mais necessário buscar uma ponte que conecte de modo seguro a consciência e os objetos. Nesse sentido, o

\footnotetext{
44 PRADINES, Maurice, Le Problème de la sensation.

45 LEVINAS, Emmanuel. Théorie de l'intuition dans la phénoménologie de Husserl, p. 138.

46 Cf. HOLMES, Richard H., Is Transcendental Phenomenology Committed to Idealism?, HALL, Harrison. Was Husserl a Realist or an Idealist?, WALLNER, Ingrid M., In Defense of Husserl's Transcendental Idealism: Roman Ingarden's Critique Reexamined, HUTCHESON, P. Husserl's Problem of Intersubjectivity.
} 
"enigma da intuição" identificado pelos críticos de Husserl, dissolve-se a partir da defesa do idealismo.

Como esclarece Levinas, por trás de tal solução está uma concepção particular de consciência enquanto uma esfera absoluta: "a noção de existência absoluta da consciência - e sua primazia com respeito a outras regiões da realidade - nos autoriza a dar credibilidade ao que a intuição reivindica"; ou seja, é somente na medida em que a consciência é prioritária em relação a outras regiões de ser que podemos confiar nos dados que ela apreende como evidentes. "A intuição é um ato cujo sentido intrínseco consiste em fornecer-nos objetos 'em pessoa'; desse modo, os dados da intuição não necessitam, para serem verdadeiro, de comparação com um ser verdadeiro independente da consciência" ${ }^{47}$. Na verdade, mais do que isso, o caráter absoluto da consciência faz com que nem mesmo seja possível tal comparação, na medida em que não há - como afirmam as polêmicas passagens "idealistas" de Husserl - nenhuma realidade independente da consciência ${ }^{48}$.

Estou de acordo com o argumento central de Patzig e Levinas - segundo o qual a teoria da verdade e da evidência foi em parte responsável pela "virada idealista" -, mas não acredito que ela tenha se dado pelas razões apresentadas. No meu ponto de vista, não foi para manter uma concepção de verdade em conexão com evidência que Husserl foi conduzido ao "idealismo", mas sim que essa sua concepção o levou a perceber os equívocos dos pressupostos que o conduziam na primeira fase de seu pensamento. Além disso, acredito que o idealismo desenvolvido por Husserl, ao menos em alguns aspectos fundamentais, representou um progresso frutífero e vantajoso da sua filosofia, de modo que tampouco concordo com a avaliação de Patzig e com as críticas, mencionadas anteriormente, de Ingarden.

Além disso, embora aceite em linhas gerais a argumentação aqui apresentada do intérprete alemão, não estou de acordo com a leitura que faz da suposta rejeição de Husserl aos graus de evidência no período de Logische Untersuchungen e, portanto, da total identidade entre evidência e verdade. Acredito, ao invés, que nesse aspecto em particular a teoria da verdade não se modificou tão substancialmente. De fato, Husserl afirma que evidência em um sentido estrito diz respeito ao ato de "uma síntese perfeita de preenchimento", mas o filósofo também reconhece que "faz sentido falar de graus e níveis de evidência" 49 . Portanto, embora em Logische Untersuchungen não seja desenvolvida

47 Ibidem, p. 153.

48 Ver também: LEVINAS, Emmanuel. En découvrant l'existence avec Husserl et Heidegger, p. 30-31.

49 HUSSERL, Edmund. Logische Untersuchungen, Hua 19/1, VI, §38, p. 651. 
uma gama tão específica de classificações e tipos de evidência como nas obras posteriores, isso não significa que Husserl já não atentasse para o fato, pois inclusive o reconhecesse explicitamente. Penso que esse teria sido, inclusive, um dos pontos problemáticos da teoria da evidência, no sentido da dificuldade de conciliá-la com o tipo de filosofia desenvolvida por Husserl nesse período.

Do mesmo modo, ainda que considere acertada, de maneira geral, a avaliação de Levinas, acredito que seja necessário analisar com cautela suas afirmações sobre a prioridade ontológica da consciência. Embora não caiba nesse estudo uma investigação detalhada da questão, é importante ter em vista que sobretudo na fase tardia do pensamento husserliano e levando em conta publicações mais recentes - algumas das quais Levinas não teve acesso - encontramos concepções mais sofisticadas do papel da consciência do que sugere a leitura levinasiana. Um exemplo bastante ilustrativo quanto a esse aspecto é a relação entre consciência e corpo, principalmente a partir da noção de corpo enquanto corpo vivo (Leib), essencialmente diferente dos demais corpos do mundo, e que aponta para uma união psicofísica. É interessante observar que todo o desenvolvimento da noção de subjetividade como ligada e vinculada a um corpo, tal como aparece na fase tardia do pensamento do filósofo alemão, coloca em cheque a leitura da fenomenologia husserliana como aquela de um ego "descarnado" e "sem mundo" 50 .

Assim, tais análises, ainda que remetam a uma série de outras questões e dificuldades dentro da fenomenologia, são suficientes para compreender, em linhas gerais, qual o entendimento de Husserl sobre os critérios para a definição de verdade e conhecimento, e o modo como tais critérios acabam por vincular o pensador alemão ao idealismo. É importante reiterar, porém, que os conceitos empregados no que diz respeito a esse tema - como intenção, evidência e verdade - são bastantes amplos e ramificados, de modo que é necessário avaliar sempre de acordo com cada contexto qual o sentido empregado.

Além disso, fica também destacado que a concepção fenomenológica de verdade desenvolvida a partir da "virada idealista" do pensamento de Husserl, ainda que possa parecer à primeira vista bastante tradicional, afasta-se da definição clássica na medida em que se mantém fiel à redução fenomenológica. Assim, uma vez que a origem de tal concepção seria em parte resultado das aporias geradas no contexto realista, surge como tarefa reavaliar o projeto fenomenológico de Logische Untersuchungen

50 Ver, por exemplo: HUSSERL, Edmund. Ideen II, §56, p. 245, HUSSERL, Edmund. Ideen II, §54, p. 214-215, HUSSERL, Edmund. Krisis, §62, p. 219, HUSSERL, Edmund. Krisis, §62, p. 175 e 219. 
à luz de sua relação com a fase idealista, assim como a própria maneira como devemos entender o idealismo husserliano e sua suposta vinculação com idealismos típicos da tradição filosófica.

\section{Referências}

ARISTOTLE. Metaphysics. Translated by W. D. Ross. Oxford: Oxford University Press, 1924.

ARISTOTLE. Nicomachean Ethics. Translated by W. D. Ross. Oxford: Oxford University Press, 1980.

BRENTANO, Franz. Psychologie vom empirischen Standpunkte. Leipzig: Duncker \& Humblot, 1974.

DESCARTES, René. Méditations métaphysiques. Paris: PUF, 1968.

DRUMMOND, John J. Historical dictionary of Husserl's philosophy. Lanham: Scarecrow Press, 2008.

DUPRE, Louis. "The Concept of Truth in Husserl". Philosophy and Phenomenological Research (1964), p. 345-354.

GUEROULT Martial, Descartes selon l'ordre des raisons. Paris: Aubier-Montaigne, 1953.

HALL, Harrison. "Was Husserl a Realist or an Idealist?". In: H.L. Dreyfus and H. Hall (eds.). Husserl, Intentionality and Cognitive Science. Cambridge, MA: MIT Press, 1982. p. 169-190.

HEIDEGGER, Martin. Sein und Zeit. Achtzehnte Auflage. Unveränderter Nachdruck der fünfzehnten, an Hand der Gesamtausgabe duchgesehenen Auflage. Tübingen: Max Niemeyer Verlag, 2001.

HEIDEGGER, Martin. Vom Wesen des Grundes. Vittorio Klostermann, 1995.

HINTIKKA, Jaakko. The notion of intuition in Husserl. Revue internationale de philosophie, 2, 224 (2003), p. 57-79.

HOLMES, Richard H., "Is Transcendental Phenomenology Committed to Idealism?". The Monist, 59 (1975).

HUSSERL, Edmund. Husserliana 1. Cartesianische Meditationen und Pariser Vorträge. Ed. Stephan Strasser. Den Haag: Martinus Nijhoff, 1950, rpt. 1973; Meditações Cartesianas e Conferências de Paris. Rio de Janeiro: Forense Universitária, 2012.

HUSSERL, Edmund. Husserliana 2. Die Idee der Phänomenologie. Fünf Vorlesungen. Ed. Walter Biemel. Den Haag: Martinus Nijhoff, 1950, rpt. 1973.

HUSSERL, Edmund. Husserliana 3, 1-2. Ideen zu einer reinen Phänomenologie undphänomenologischen Philosophie. Erstes Buch. Allgemeine Einfuhrung in die reine Phänomenologie. Ed. Karl Schuhmann. Den Haag: Martinus Nijhoff, 1976; Ideias para uma Fenomenologia Pura e para uma Filosofia Fenomenológica. São Paulo: Ideias e Letras, 2006.

HUSSERL, Edmund. Husserliana 4. Ideen zu einer reinen Phänomenologie und phänomenologischen Philosophie. Zweites Buch. Phänomenologische Untersuchungen zur Konstitution. Ed. Marly Biemel. The Hague: Martinus Nijhoff, 1952. 
HUSSERL, Edmund. Husserliana 6. Die Krisis der europäischen Wissenschaften und die transzendentale Phänomenologie. Eine Einleitung in diephänomenologische Philosophie. Ed. Walter Biemel. The Hague: Martinus Nijhoff, 1954, rpt. 1962; A crise das ciências europeias e a fenomenologia transcendental. São Paulo: Forense Universitária, 2012.

HUSSERL, Edmund. Husserliana 17. Formale und transzendentale Logik. Versuch einer Kritik der logischen Vernunft. Ed. Paul Janssen. The Hague: Martinus Nijhoff, 1974.

HUSSERL, Edmund. Husserliana 18. Logische Untersuchungen. Erster Band. Prolegomena zur reinen Logik. Ed. Elmar Holenstein. The Hague: Martinus Nijhoff, 1975.

HUSSERL, Edmund. Husserliana 20. Logische Untersuchungen. Ergänzungsband. Erster Teil. Ed. Ullrich Meile. Dordrecht: Kluwer Academic Publishers, 2002.

HUSSERL, Edmund. Husserliana 24. Einleitung in die Logik und Erkenntnistheorie. Vorlesungen 1906/7. Ed. Ullrich Meile. Dordrecht: Martinus Nijhoff, 1984.

HUSSERL, Edmund. Erfahrung und Urteil: Untersuchungen zur Genealogie der Logik. Ed. L. Landgrebe. Prague: Academia-Verlag, 1939.

HUTCHESON, P. "Husserl's Problem of Intersubjectivity." Journal of the British Society for Phenomenology, 11 (1980), p. 144-162.

INGARDEN, Roman. On the motives which led Husserl to transcendental idealism. Martinus Nijhoff, 1975.

INGARDEN, Roman. "Meine Erinnerungen an Edmund Husserl". In: Edmund Husserl: Briefe an Roman Ingarden. Mit Erläuterungen Und Erinnerungen an Husserl. The Hague: Martinus Nijhoff. Phaenomenologica, 25 (1968).

LEVINAS, Emmanuel. En découvrant l'existence avec Husserl et Heidegger. Paris: Vrin, 1982.

LEVINAS, Emmanuel. Théorie de l'intuition dans la phénoménologie de Husserl. Paris: Vrin, 1963.

MCGILL, V. J. "Evidence in Husserl's Phenomenology". In: Phenomenology: Continuation and Criticism. Springer Netherlands, 1973. p. 145-166.

PATZIG, Günther. „Kritische Bemerkungen zu Husserls Thesen über das Verhältnis von Wahrheit und Evidenz. “ Edmund Husserl 1859-2009: Beiträge aus Anlass der 150. Wiederkehr des Geburtstages des Philosophen, 14 (2011), p. 57-76.

PATZIG, Günther. "Husserl on Truth and Evidence". In: Readings on Edmund Husserl's Logical Investigations, ed. J.N. Mohanty, The Hague: Martinus Nijhoff, 1977. p. 179-196.

PRADINES, Maurice, Le Problème de la sensation. Paris: Alcan, 1928.

RUSSELL, Matheson. Husserl: A Guide for the Perplexed. London: Continuum, 2006.

SOKOLOWSKI, Robert, Introduction to Phenomenology. New York: Cambridge University Press, 2000.

STRÖKER, Elisabeth. „Husserls Evidenzprinzip. Sinn und Grenzen einer methodischen Norm der Phänomenologie als Wissenschaft. Für Ludwig Landgrebe zum 75. Geburtstag“. Zeitschrift für philosophische Forschung (1978), p. 3-30. 
TUGENDHAT, Ernst. Der wahrheitsbegriff bei Husserl und Heidegger. Walter de Gruyter, 1970.

TUGENDHAT, Ernst. Heideggers Idee von Wahrheit. In: Heidegger: Perspektiven zur Deutung seines Werks. Ed. Otto Pöggeler. Cologne: Kiepenheuer und Witsch, 1969.

VÁSQUEZ, Guillermo Hoyos. "Von der Adäquaten zur Apodiktischen Evidenz". In: Intentionalität als Verantwortung. Springer Netherlands, 1976. p. 149-172.

WALLNER, Ingrid M. "In Defense of Husserl's Transcendental Idealism: Roman Ingarden's Critique Reexamined”. Husserl Studies, 4 (1987).

ZAHAVI, Dan. Husserl's Phenomenology. California: Stanford University Press, 2003.

\section{Endereço postal:}

Universidade Católica de Pernambuco

Centro de Teologia e Ciências Humanas

Rua do Príncipe, 526 - Boa Vista

Recife, PE, Brasil

Data de recebimento: 11-09-2016

Data de aceite: 23-11-2016 